\title{
ATENDIMENTO HOSPITALAR A PACIENTES ESPECIAIS
}

Monica Zeni REFOSCO, Aline SINEGALIA, Guilherme Degani BATTISTETTI, Luiz Omar WEILLER, Edo HIRATA, Adriano Tomio HOSHI

O paciente portador de necessidades especiais é todo o indivíduo que apresenta determinados desvios dos padrões de normalidade, identificáveis ou não, e que, por isso, necessitam de atenção e abordagem especiais por um período de sua vida ou indefinidamente. Os pacientes portadores de necessidades especiais têm o mesmo direito de acesso ao tratamento odontológico, seja ele realizado em ambulatório ou em ambiente hospitalar. Este trabalho apresentará um caso clínico de atendimento a uma paciente portadora de necessidades especiais, realizado sob anestesia geral. Tratou-se de uma paciente do gênero feminino, com 17 anos de idade, que foi encaminhada ao Centro de Especialidades Odontológicas da UNIOESTE Cascavel. $\mathrm{Na}$ anamnese foi relatado que a paciente era portadora de paralisia cerebral grave. No exame intrabucal, verificou-se que todos os dentes apresentavam lesões de cárie extensas e/ou mobilidade devido à doença periodontal. Como houve muita dificuldade para realização de contenção física e devido à necessidade de extração de todos os dentes, a paciente foi encaminhada para a equipe da residência em Cirurgia e Traumatologia Bucomaxilofacial para realização do tratamento sob anestesia geral. Conclui-se que, quando bem indicada, a anestesia geral tem resultado positivo, pois dá tranqüilidade ao cirurgião-dentista para executar seu trabalho e maior segurança e conforto ao paciente e familiares.

Palavras-chave: Odontologia para deficientes; Anestesia geral, Saúde bucal. 